\title{
LA IMPORTANCIA DEL LIDERAZGO ACADÉMICO EN LA GESTIÓN DE LAS REVISTAS CIENTÍFICAS: EL CASO DIÁLOGO ANDINO*
}

\author{
THE IMPORTANCE OF ACADEMIC LEADERSHIP IN THE MANAGEMENT \\ OF SCIENTIFIC JOURNALS: DIALOGO ANDINO CASE
}

\author{
Álvaro Palma Quiroz ${ }^{* *}$,Emilio Rodríguez-Ponce ${ }^{* * *}$
}

Una revista especializada constituye un terreno donde la esencia de su quehacer es el razonamiento. Sin duda, por su naturaleza una publicación científica debe ser un espacio para el diálogo académico, para la reflexión, para la exposición de ideas y tesis novedosas, para el contraste de argumentos. En fin, dicho claramente, un espacio para el debate académico.

Ahora bien, las publicaciones científicas se han ido profesionalizando cada vez con mayor profundidad. Esto por cuanto como toda actividad que requiere de recursos económicos, que suelen ser escasos frente a las múltiples necesidades de las instituciones, requieren tanto procesos de optimización, como el logro de resultados académicos reales y efectivos.

No se trata de estandarizar la reflexión académica, sino que más bien el propósito es insertar las revistas como un espacio de debate, pero que requiere gestión. Gestión para compararse entre sus pares, gestión para posicionarse, gestión para lograr sus fines académicos, gestión para rendir cuenta por los recursos empleados.

En la sociedad del conocimiento, la fuente esencial de la ventaja competitiva de las naciones, las organizaciones y las personas reside precisamente en el conocimiento. Gestionar una revista científica es gestionar conocimiento y esta es una tarea de suyo compleja y, por consiguiente, la gestión del conocimiento es uno de los aspectos más determinantes del éxito en el ámbito de las publicaciones científicas.

Muchos son los elementos a considerar para una gestión de las publicaciones científicas. Sin embargo, el liderazgo es una dimensión crítica. En efecto, el liderazgo se refiere a la capacidad de influir sobre los individuos de un equipo o grupo con la finalidad de generar una determinada actuación o comportamiento en favor de alcanzar los objetivos propuestos para ese grupo o equipo. El liderazgo es, por lo tanto, una dimensión susceptible de ser aplicada cada vez que se esté en presencia de un grupo o equipo de individuos que procuran alcanzar determinados objetivos.

Los avances experimentados por la Revista Diálogo Andino sirve como un valioso ejemplo para identificar un conjunto de rasgos distintivos del liderazgo académico exhibido en la misma, los que han permitido un crecimiento cualitativo muy significativo en los últimos años. Entre tales características cabe destacar las siguientes:

Liderazgo distribuido: que emerge desde la alta dirección universitaria hasta los especialistas, llámese director, comité editor, staff de administración o árbitros. Es decir, la máxima dirección de la institución que alberga la revista debe preocuparse de la misma asignando los recursos pertinentes, así como brindando el empoderamiento que cada miembro requiere para realizar un conjunto de tareas integradas, con sinergias, sumando esfuerzos para una finalidad compartida.

> Generación de objetivos desafiantes: se trata de la definición de objetivos ciertamente posibles, pero, a la vez, difíciles de alcanzar. Visión que en la primera década de este siglo permitió lograr que la revista fuera reconocida por Scientific Electronical Library Online y

\footnotetext{
* Agradecimientos: Proyecto FONDECYT Regular 1170960 y Convenio de Desempeño UTA-MINEDUC.

** Universidad de Tarapacá, Escuela Universitaria de Negocios y Administración. Arica, Chile. Correo electrónico: apalma@ uta.cl

*** Universidad de Tarapacá, Instituto de Alta Investigación. Correo electrónico: erodriguez@uta.cl
} 
que en la presente década llegó a acceder a un reconocimiento de Scopus. El desafío emergente es ser incorporada, en un futuro mediato, en Web of Science-Core Collection.

\section{> Construcción de un clima moral orientado}

a la eficacia: donde se reconocen los aportes individuales para los logros colectivos. Construcción que se ha cristalizado incluso en convenios de desempeño entre la Revista y la alta dirección universitaria, brindándose amplios márgenes de maniobra para el mejor despliegue de los talentos de los especialistas, en un contexto de control sistemático por el logro de objetivos.

\section{> Una dirección respetada académicamente:} en el proceso de selección de la dirección de la Revista se ha elegido académicos reputados en la disciplina, con capacidad para investigar y publicar al mayor nivel mundial, lo cual ha influido en la atracción de pares, nacionales e internacionales, que han postulado sus trabajos a la Revista, junto con un esfuerzo y compromiso notable del área de trabajo para brindar lo mejor de su labor académica.

\section{Una motivación que inspira al progreso: que} ha unido esfuerzos desde la alta dirección universitaria y específicamente a partir de la dirección de la Revista para construir una orientación de un futuro deseable, compartiendo esta visión con su equipo y logrando que sus seguidores se sientan copartícipes e importantes para lograr ese futuro. Cada miembro de la Revista sabe el valor de su trabajo y cada uno sabe que su rol es esencial para lograr el futuro diseñado, por lo que trabajan en un clima de colaboración y respeto.

Fomento a la innovación y la creatividad: se estimulan las nuevas ideas, las nuevas soluciones y existe posibilidad de asumir riesgos moderados para dar saltos cualitativos en la Revista. Esta ha ido incorporando mejoras tecnológicas, ampliando sus horizontes de trabajo, fortaleciendo su staff de evaluadores y su comité editorial con un norte claro y con una dirección volcada a conseguir los mayores logros en el más breve plazo.

Por cierto, quedan muchos aspectos por mejorar, pero sin ninguna ambigüedad se puede plantear que: Diálogo Andino Revista de Historia, Geografía y Cultura Andina, es una revista que cumple cabalmente con el objetivo esencial, publicar artículos originales y resultados de investigaciones especializadas en los campos de la Historia, la Etnohistoria, la Geografía Cultural, la Etnografía o disciplinas afines de las Humanidades y de las Ciencias Sociales que aborden aspectos circunscritos al área geocultural de Los Andes o de otros contextos regionales y socioculturales. Los artículos son cada vez de mayor calidad, existe mayor cantidad de trabajos sometidos a evaluación, la cobertura geográfica toca con fuerza la Región Andina en forma, cada vez, más exhaustiva, los árbitros se tornan más exigentes y los tiempos de evaluación son eficientes en relación con publicaciones de complejidad equivalente.

Diálogo Andino es un ejemplo relevante de cómo gestionar eficientemente el conocimiento, reconociendo la importancia y rol que le cabe al liderazgo académico en este avance y progreso de esta significativa Revista de la Universidad de Tarapacá. 